Dept. of Infectious Diseases,

Faculty of Veterinary Medicine, Beni-Suef University

\title{
FAILURE OF CONTROL OF BRUCELLA MELITENSIS INFECTION IN A DAIRY HERD
}

(With 2 Tables and 4 Figures)

By

\author{
R.A. AZZAM; A.M. EL-GAMAL* \\ and M.T. ELSHEEMY ** \\ * Dept of Bacteriology, Mansoura Lab., \\ Animal Health Research Institute
}

** Dept of Infectious Diseases, Faculty of Veterinary Medicine,

Alexandria University

(Received at 11/3/2009)

\section{فثل السيطرة على عدوى البرويسلا مليتنز فى قطيع أبقار حلابة}

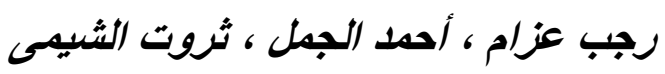

أجريت هذه الدراسة على عدد 451 حيو انا فى مزرعة للابقار الفريزيان الحلاب بمحافظة

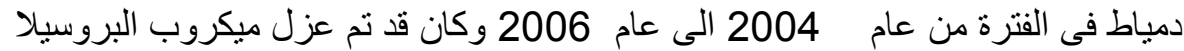

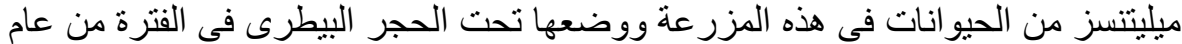

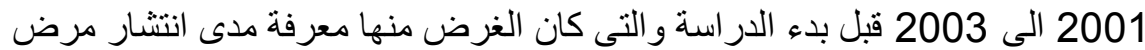

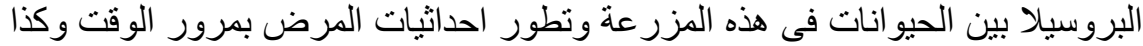

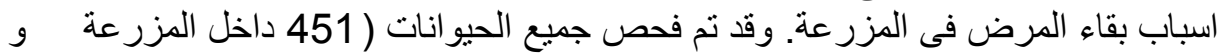

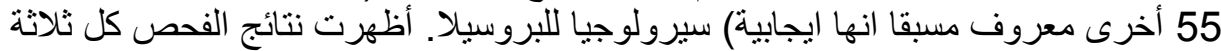

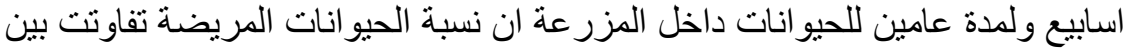

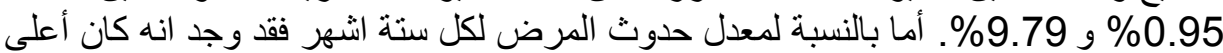

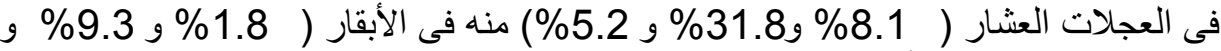

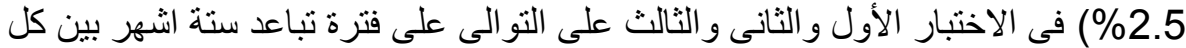

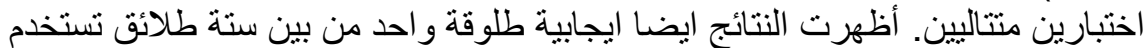

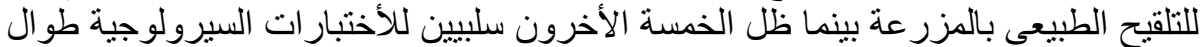

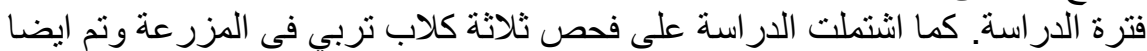

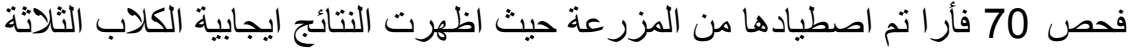

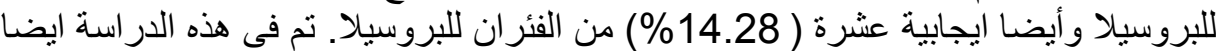

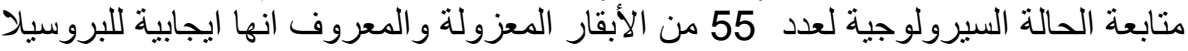

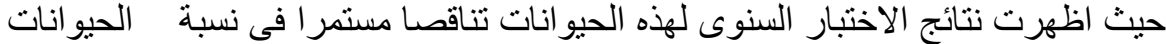

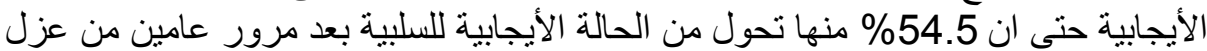

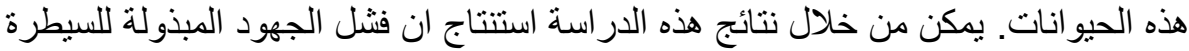

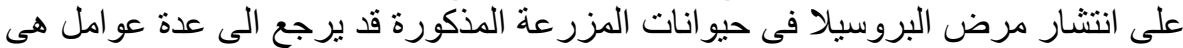




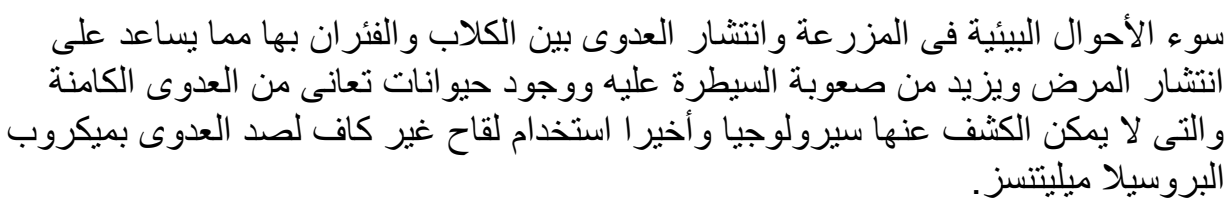

\section{SUMMARY}

This study was carried out during the period 2004- 2006 to follow up the pattern of occurrence of brucellosis in a farm of dairy Friesian cattle (in Damitta Governorate, Egypt) from which B. melitensis biotype 3 had been previously isolated and the farm had been put under quarantine of veterinary authorities through the period 2001-2003. All animals inside the farm including 451 cows, 49 pregnant heifers and 6 bulls were serologically tested using RBT, TAT and Riv. test at three weeks intervals for two years. The results showed that the prevalence of brucellosis ranged from $0.95 \%$ to $9.79 \%$. The incidence (every 6 months) of brucellosis was always higher in pregnant heifers $(8.1 \%$, $31.8 \%$ and $5.2 \%)$ than in mature cows $(1.8 \%, 9.3 \%$ and $2.5 \%)$ in the first, second and third examination respectively. Concerning bulls, only one $(16.6 \%)$ was found positive at the beginning of our study. None of the other 5 bulls seroconverted during period of the study. The study also included 3 dogs and 70 rats that were trapped in the farm where all the dogs and $10(14.28 \%)$ of the rats were positive for brucellosis by the same tests. Besides, 55 high milk producing positive cows that had been isolated in an independent place and separately milked for more than 2 years were annually tested using RBT, TAT and CFT to follow up the changes in their serological status. The results of annual serological examination of these cows revealed that there was a continuous decline in the percentage of positive animals where by the end of the study; 22 $(45.5 \%)$ out of the 55 positive cows reverted to the negative serological status. It was concluded that, despite efforts, Failure to control infection for this long time was thought to be due to the bad hygienic conditions, presence of infected dogs and rats, presence latently infected heifers and the use of RB51 vaccine that does not confer complete protection against $B$. melitensis infection.

Key words: Cattle Brucellosis, brucella melitensis, vaccination

INTRODUCTION 
Brucellosis is a worldwide zoonotic disease caused by the facultative intracellular members of the bacterial genus Brucella of which at least six species are now recognized; these are highly genetically homogenous, and the disease is of major socio-economic importance, Commander et al. (2002).

The disease still constitutes a great threatening challenge to livestock breeding allover the world despite being successfully eradicated from many developed countries. Eradication programmes in these countries depended largely on testing and slaughtering of positive animals, Robinson (2003).

Bovine brucellosis is typically caused by B.abortus since it was discovered by Bang. Yet, in some areas of the world, B.melitensis has emerged as a cause of brucellosis in cattle beside goats, sheep and man, International conference on emerging zoonoses (1997) and OIE Terrestrial Manual (2008).

When bovine brucellosis is caused by B.abortus, the disease causes a storm of abortion in free herds followed by reproductive problems and sporadic cases of abortion in the subsequent seasons while only sporadic cases of abortion are experienced when the disease is caused by B.melitensis because cattle is not the preference host of the later organism, Hosein (2005).

In developing countries, poor economic capacity, Mobarak et al. (2000), use of conventional routine methods of diagnosis which lack high accuracy, Rajaii et al. (2006), and the poor public knowledge of the disease greatly tie up the development of successful eradication programmes.

In Egypt, brucellosis is an endemic zoonotic disease that greatly affects both animal health and human health despite the exhaustive efforts to control the disease.

Control programmes in Egypt, like most of the developing countries, are based on test and slaughter of positive animals and mass vaccination. Yet, the disease still constitutes an obstacle in the way of developing our animal health by official veterinary authorities, veterinarians and breeders, El-minshawy (2007).

The present work was carried out to investigate the possible strategies maintenance of brucellosis in dairy cattle populations. 


\section{Animals}

The following animals were employed in this study

\section{A. Cattle:}

a. Group I animals:

A total of 451 Friesian dairy cows, 49 pregnant heifers and 6 bulls (for natural insemination) in a dairy farm in Damitta Governorate (This farm was previously brucellosis positive and had been quarantined through the period 2001-2003).

N.B: Animals in the farm were annually vaccinated using RB51 vaccine.

b. Group II animals:

Brucellosis positive highly lactating cows (55 cows) that were kept in a separate unit away from free animals and their milk was treated as brucella infected.

B. Dogs: Three (3) dogs that had been kept in the farm.

C. Rats: A total of 70 wild rats were trapped in the farm and involved in the study.

2. Antigens: Antigens for tube agglutination test (TAT), Buffered acidified plate antigen test (BAPAT), Rose Bengal plate test (RBT) and Rivanol test (Riv) as well as Rivanol solution were obtained from Veterinary Serum and Vaccine Research Institute, Abbasia, Cairo, Egypt. License No. 188 was obtained from professional biological company 4950York Street-Denver, Co, USA.

Antigen for CFT was offered by the National Veterinary Services Laboratory (NVSL), Ames, IWA 50010, USA.

3. Medium: Tryptic soya agar, Difco laboratories, Detroit, MI, USA was used for culturing Brucella organisms.

Tube agglutination, Buffered acidified plate agglutination and Rivanol tests were carried out according to Alton et al. (1988). Rose Bengal test was carried out according to Morgan et al. (1978). CFT was carried out according to warm microtechnique described by Alton et al. (1988).

Isolation, Identification and typing of Brucella organisms were performed according to the methods described by Alton et al. (1988).

\section{Design of work:}

a. Animals in Group I were serologically tested for brucellosis using RBT, TAT and Riv. The tests was applied at three weeks intervals for two years to follow up the pattern of brucella infection in such population; an animal was classified as positive when it was found positive to two tests or more (one of which must be Riv test). 
b. Animals in Group II were serologically tested annually using TAT, BAPAT and CFT to monitor the changes in both their serological status and their antibody titers to brucella in relation to time; an animal was classified as positive when it was confirmed as positive by CFT.

c. Dogs and rats were tested for brucellosis using RBT and Riv test only once where dogs were eliminated and rats were killed.

\section{RESULTS and DISCUSSION}

Because of the persistence of the disease in animals of Group I, we continued to test them at 3 weeks intervals for two (2) years. Positive animals were slaughtered after each test. We found that it is more practical and more reasonable to show the results to express the incidence of brucellosis every 6 months, Table (1), because the incidence can be more expressive for the pattern of occurrence of brucellosis in these animals, Pfeiffer (2002).

Table 1: Following up the serological examination of group (I) animals (Incidence at six-month periods)

\begin{tabular}{|c|c|c|c|c|c|c|}
\hline Period & Total & \multicolumn{2}{|c|}{ Animals } & Number & Positive & Total positive \\
\hline \multirow{3}{*}{$\begin{array}{l}\text { First } \\
\text { period }\end{array}$} & \multirow{3}{*}{493} & \multicolumn{2}{|l|}{ Cows } & 438 & $8(1.82 \%)$ & \multirow{3}{*}{$13(2.63 \%)$} \\
\hline & & \multicolumn{2}{|c|}{ Pregnant heifers } & 49 & $4(8.16 \%)^{*}$ & \\
\hline & & \multicolumn{2}{|l|}{ Bulls } & 6 & $1(16.66 \%)$ & \\
\hline \multirow{4}{*}{$\begin{array}{l}\text { Second } \\
\text { period }\end{array}$} & \multirow{4}{*}{480} & \multicolumn{2}{|l|}{ Cows } & 430 & $40(9.30 \%)$ & \multirow{4}{*}{$47(9.79 \%)$} \\
\hline & & \multirow{2}{*}{ heifers } & Pregnant & 22 & $7(31.81 \%)^{*}$ & \\
\hline & & & Delivered & 23 & 0 & \\
\hline & & \multicolumn{2}{|l|}{ Bulls } & 5 & 0 & \\
\hline \multirow{3}{*}{$\begin{array}{l}\text { Third } \\
\text { period }\end{array}$} & \multirow{3}{*}{433} & \multicolumn{2}{|l|}{ Cows } & 390 & $10(2.56 \%)$ & \multirow{3}{*}{$12(2.77 \%)$} \\
\hline & & \multicolumn{2}{|c|}{ Delivered heifers } & 38 & $2(5.26 \%)^{*}$ & \\
\hline & & \multicolumn{2}{|l|}{ Bulls } & 5 & 0 & \\
\hline \multirow{3}{*}{$\begin{array}{l}\text { Fourth } \\
\text { period }\end{array}$} & \multirow{3}{*}{421} & \multicolumn{2}{|l|}{ Cows } & 380 & $4(1.05 \%)$ & \multirow{3}{*}{$4(0.95 \%)$} \\
\hline & & \multicolumn{2}{|c|}{ Previously heifers } & 36 & 0 & \\
\hline & & \multicolumn{2}{|l|}{ Bulls } & 5 & 0 & \\
\hline
\end{tabular}

* All the positive heifers were born to positive dams that had been eliminated (Farm records). 
Table 2: Results of serological examination of group (II) animals

\begin{tabular}{|c|c|c|c|c|c|c|c|c|c|c|c|c|c|c|}
\hline Test & \multicolumn{5}{|c|}{$\begin{array}{l}\text { RBT } \\
\text { (Degree of reaction) }\end{array}$} & \multicolumn{5}{|c|}{ TAT (Titers) } & \multicolumn{4}{|c|}{ CFT (Titers) } \\
\hline $\begin{array}{l}\text { Examined } \\
\text { animals }\end{array}$ & $\begin{array}{l}+ \\
1\end{array}$ & $\begin{array}{l}+ \\
2\end{array}$ & $\begin{array}{l}+ \\
3\end{array}$ & $\begin{array}{l}+ \\
4\end{array}$ & $\begin{array}{l}\text { Total } \\
\text { Positive }\end{array}$ & $\begin{array}{l}1 / \\
2 \\
0\end{array}$ & $\begin{array}{l}1 / \\
4 \\
0\end{array}$ & $\begin{array}{l}1 / \\
80\end{array}$ & $\begin{array}{l}1 / 1 \\
60\end{array}$ & $\begin{array}{l}\text { Total } \\
\text { Positive }\end{array}$ & 1 & $\begin{array}{l}1 / \\
16\end{array}$ & $\begin{array}{l}1 / \\
32\end{array}$ & $\begin{array}{l}\text { Total } \\
\text { Positiv } \\
\text { e }\end{array}$ \\
\hline First (55) & 3 & $\begin{array}{l}1 \\
4\end{array}$ & $\begin{array}{l}3 \\
0\end{array}$ & 8 & $\begin{array}{l}55 \\
(100 \%)\end{array}$ & 7 & $\begin{array}{l}3 \\
2\end{array}$ & 10 & 1 & $\begin{array}{l}43 \\
(78.2 \%)\end{array}$ & 2 & 40 & 3 & $\begin{array}{l}55 \\
(100 \%\end{array}$ \\
\hline Secon (55) & 0 & $\begin{array}{l}1 \\
0\end{array}$ & $\begin{array}{l}2 \\
7\end{array}$ & 6 & $\begin{array}{l}43 \\
(78.2 \%)\end{array}$ & $\begin{array}{l}1 \\
0\end{array}$ & $\begin{array}{l}2 \\
7\end{array}$ & 6 & 0 & $\begin{array}{l}33 \\
(60 \%)\end{array}$ & 0 & 22 & 1 & $\begin{array}{l}43 \\
(78.2 \%\end{array}$ \\
\hline Third (55) & 0 & $\begin{array}{l}1 \\
5\end{array}$ & $\begin{array}{l}1 \\
3\end{array}$ & 2 & $\begin{array}{l}30 \\
(54.5 \%)\end{array}$ & 6 & $\begin{array}{l}2 \\
2\end{array}$ & 2 & 0 & $\begin{array}{l}24 \\
(43.6 \%)\end{array}$ & 1 & 12 & 0 & $\begin{array}{l}30 \\
(54.5 \%\end{array}$ \\
\hline
\end{tabular}
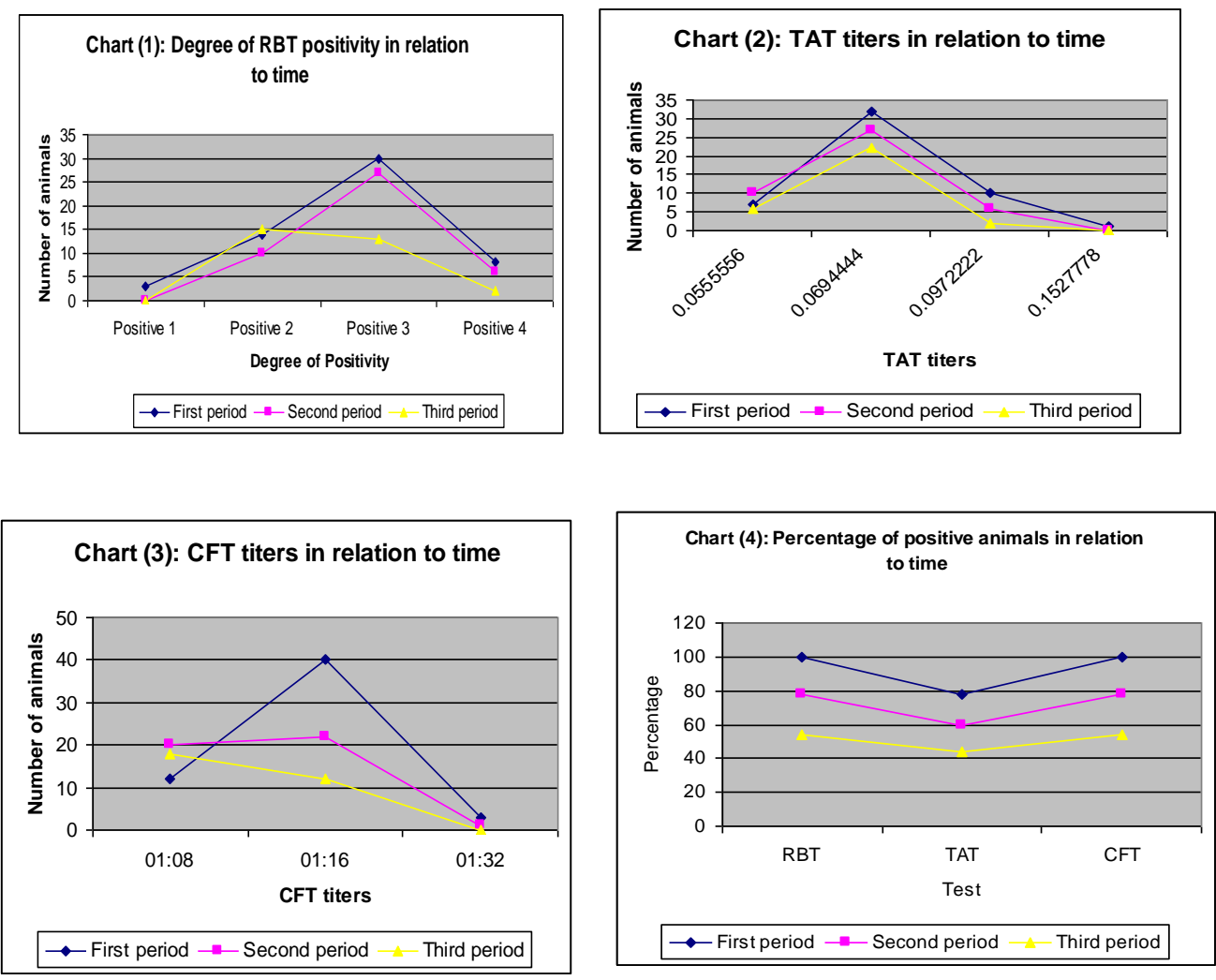
The results of serological examination of animals in group I (Table1) showed that the incidence of brucellosis (new animals that seroconverted during a period of six months) ranged from $9.79 \%$. (In the second 6-month-period) to $0.95 \%$ (in the last 6-month-period).

It is known that the prevalence and incidence of brucellosis vary greatly from country to country, International conference on emerging zoonoses (1997) and even between herds in the same locality as reported by Francisco and Vargas (2002). In Egypt, variation in prevalence of brucellosis among cattle have been made clear by many authors including Hosein et al. (2002); 2.3-15.6\%, EL-diasty (2004);4.95-5.8\% and Khoudair and Safenaze (2007); $2.1 \%$. These variations are usually due to the variation in methods of husbandry in different localities and the different employed serological tests, Robinson (2003). In our study, the variation was in the same herd by time and for a period of 2 years indicating the existence and persistence of some maintenance factors in this herd, Hosein et al. (2001).

The results in (Table 1) showed that the incidence of brucellosis was always higher in pregnant heifers and heifers that already gave birth $(8.16 \%, 31.81 \%$ and $5.26 \%)$ than in mature cows $(1.82 \%, 9.30 \%$ and $2.56 \%$ ) in the first, second and third periods respectively. This was disagreed with the results of many authors as Botha and Williamson (1989), Muranalini and Ramasastry (1999) and Amin et al. (2005) who reported that the prevalence of brucellosis was higher in older mature cows than heifers due to the higher exposure and the stress of pregnancy and activation of latent infection. However, in our study all the positive heifers (11) turned positive after the $5^{\text {th }}$ month of pregnancy and all were born to seropositive cows that had been culled to another separate place. These findings indicated that these heifers were latently infected and seroconverted during pregnancy, Leal-Hernandez et al. (2005). It was also found that Positive cases could still be recorded among adult cows till the end of the study period by which there were $4(1.05 \%)$ positive cows out of 380 cows.

Concerning bulls, only one out of 6 bulls (16.66\%) was found positive at the beginning of our study. None of the other 5 bulls seroconverted. This indicates that venereal transmission is rare in B.melitensis infection, Lorraine (2004). Moreover, bulls were separated from cows and their exposure was much lower than cows.

The highest incidence of brucellosis in the farm was reported in the second 6-month-period where it jumped from $2.63 \%$ in the first six months to $9.79 \%$. This means that the disease still persists in the herd 
despite slaughtering of positive animals and mass vaccination using RB51 vaccine indicating that these measures were not sufficient to prevent the spread of brucellosis. Hence, an active brucella infection which facilitated transmission of the infection from cow to cow, ElDiasty (2004) might be the cause. Vaccination using RB51 (B.abortus strain) is known to be insufficient to protect against B.melitensis infection as reported by Hosein et al. (2005b) and Perry (2007).

However, brucellosis-positive animals continued to be detected for a period of other one year where the incidence was $2.77 \%$ in the third period and $0.95 \%$ during the last 6-month-period of the study. This indicates the endemic nature of the disease in the herd, Pfeiffer (2002) and the insufficiency of the adopted control measures.

Because so many rats were seen in this farm, we had to test if these were infected; the results of serological testing of 70 rats revealed that $(14.28 \%)$ were positive (Table 1) and they might facilitated the spread of infection among cows as reported by Hosein et al. (2001). Moreover, the three dogs that were kept in the farm were found serologically positive for brucellosis (Table 1) and, as carriers, they might have played a role in transmission and maintenance of infection among cattle in the farm, Hosein et al. (2005a).

As control measures, continuous deratization of rats and culling of positive animals lead the incidence of the disease to decline to $2.77 \%$ by the end of the third 6 months period; this augments clear the doubt about their role in the spread of infection, Mahrous, (2002). Despite declined incidence was still in the range as it was at the beginning of our study indicating that either there are other causes for the maintenance of brucellosis in the farm or inefficient control measures.

Concerning animals in group II; these were 55 high milk producing cows that were kept despite being seropositive. They showed no reproductive disturbances and bred normally despite being brucella melitensis infected. This normal status of infected cows might be due to the fact that even with $B$. abortus infection, some infected cows will not exhibit any clinical symptoms of the disease and give birth to normal calve, Perry (2007). In case B. melitensis, infection of cattle there are still doubts about the tendency of this organism to colonize. In the uterus of pregnant cows sufficiently to cause abortion, Shalaby (1986). This might account for the occurrence of only sporadic cases of abortion in cattle with $B$. melitensis infection rather than outbreaks of abortion in case of B. abortus infection, Hosein (2005). 
The results of the first serological examination of animals of group II, Table (2) revealed that all cows 55(100\%) could be classified as positive using RBT and CFT while only 43 cows (78.2\%) were positive using TAT while other 7 (12.7\%) cows had inconclusive titers. Failure of TAT (more IgM dependent) to classify 12 (21.8\%) of cows as positive might be due to the chronicity of the disease in such animals where IgM had declined while RBT and CFT (IGg dependent) still could detect these chronically infected animals, Radostits et al. (2000).

Testing these animals for the second and third time at one year intervals revealed that there was a significant decline in the numbers of serologically positive animals as compared to the first examination by any of the employed tests. In the second examination, 33 cows (60\%) were positive by TAT while 43 cows $(78.2 \%)$ were positive by RBT and CFT. The numbers of positive animals continued to decline in the third examination where only 24 cows $(43.6 \%)$ were positive by TAT and 30 $(54.5 \%)$ were positive by RBT and CFT. Similar results were reported by El-minshawy (2007).

As shown in Chart (1), Out of 8 animals that were (+4) for RBT in the first examination, only 2 retained their antibody titers until the last examination. Similarly, the titers of TAT and CFT declined from 10 animals with titers of $(1 / 80)$ in the first examination to 2 animals in the last one for TAT (Chart 2) and from 40 animals with titers of (1/16) in the first examination to 12 animals in the last one for CFT (Chart 2). Interpreting the results of the employed tests individually indicated that these animals revert to seronegative status due to the gradual decline of immunoglobline titers. Interpreting the results of the employed tests individually indicated that these animals revert to seronegative status due to the gradual decline of immunoglobline titers and the more specificity of CFT in detection of chronic cases of brucellosis as it can detect traces of IgG, Radostits et al. (2000). The results in (Chart 4) showed that the percentage of positive animals declined from 100 to 54.5 by RBT, from 78.2 to 43.6 by TAT and from 100 to 54.5 by CFT.

It is worthy to mention that, converting into seronegative status for an animal does not necessarily mean that such animal is bacteriologically free. These seronegative animals might have reverted to latency, Sözmen et al. (2004). Keeping such infected animals even when they are seronegative is in our point of view is hazardous to both animal wealth and human health and further investigation is needed to determine the infectious status of these animals. 
It was concluded that, despite efforts, Failure to control infection for this long time was thought to be due to the bad hygienic conditions, presence of infected dogs and rats, presence latently infected heifers and the use of RB51 vaccine that does not confer complete protection against $B$. melitensis infection.

\section{REFERENCES}

Alton, G.G.; Jones, L.M.; Angus, R.D. and Verger, J.M. (1988): Techniques for the Brucellosis laboratory. INRA, Publication, Paris, ISEN, France.

Amin, M.R.; Kazi, M.; Bahanur Rahman, M.; Siddiqur Rahman; Jaecheol Han; Jin-ho Park and Joon-seok Chae (2005): Prevalence of Brucella antibodies in sera of cows in Bangladesh J. Vet. Sci. (2005), 6(3), 223-226

Botha, C.J. and Williamson, C.C. (1989): A serological survey of bovine brucellosis in four districts of Bophuthatswana. Vet Bull 50, 716.

Commander, N.J.; Vickers, A.; Cutler, S; Wren, B. and MacMillan, A.P. (2002): DNA based vaccines for protection of man and animals against brucellosis. 55th Annual Brucellosis Research Conference November 9-10, 2002 Millennium Hotel St. Louis, MO.

El-Diasty, M.M. (2004): Some epidemiological and immunological studies on cattle brucellosis. M.V.Sc. Thesis (Inf. Dis.), Faculty of Vet. Med., Ismalia, Suez Canal University.

El-minshawy, A.S. (2007): MVSc thesis, Infect. Dis. Fac. Vet. Med. Beni-Suef University.

Francisco, J. and Vargas O. (2002): Brucellosis in Venezuela Veterinary Microbiology 90 (2002) 39-44

Hosein, H.I. (2005): Textbook "Infectious diseases of domestic animals" Lazer center publication and distribution, Beni-suef. ISSN: 9771713833

Hosein, H.I.; Dawood, F.Z. and El-Sheery, M.N. (2002): Evaluation of the policy of test and slaughter for control of brucellosis in Egypt. $10^{\text {th }}$ Sci. Con. 2002, Fac. Vet. Med. Assiut Univ., Egypt.

Hosein, H.I.; El-Sheary, M.N.; El-Sherif, A.M. and Ibrahim K.M.S. (2005a): Field evaluation of the rough mutant Brucella abortus RB 51 vaccine in cattle. Beni-Suef Vet. Med. J. Vol. 15, No. 2, 252-254. 
Hosein, H.I.; Shalaby, M.N. and Azzam, R.A. (2005b): Abortion and shedding of Brucella abortus RB51 in vaginal exudates of vaccinated cows Beni-Suef Vet Med J (2005) Vol. 15, No. 2, 268-270.

Hosein, H.I.; Sohair, Y.; Enany, M. and Gabal, M.A. (2001): The role of some brucella carriers (Stray dogs and cats) in maintenance of brucella infection. Beni-Suef Vet. Med.J. (2), 521.

International conference on emerging zoonoses (1997): Brucellosis: an overview, Emerging Infectious Diseases Vol. 3, No. 2, AprilJune 1997.

Khoudair, R.M. and Safenaz, S.A. (2007): Bacteriological, serological and pathological studies in buffaloes naturally infected with brucellosis. Egy. J. Comp. Path. \& Clinic. Path. Vol. 20 No. 1 (March) 2007; 309-332

Leal-Hernandeza Marisela.; Efre'n Di'az-Apariciob,; Rafael Pe'reza; Laura Herna'ndez Andradeb; Beatriz Arellano-Reynosob, Edgar Alfonsecac and Francisco Sua'rez-Güemes (2005): Protection of Brucella abortus RB51 revaccinated cows, introduced in a herd with active Brucellosis, with presence of atypical humoral response Comp. Immunolo. Microbiol. Infect. Dis. 28 (2005) 6370.

Lorraine, H.M. (2004): Evaluation of rough Brucella strains as vaccines for brucellosis and pseudorabies in swine. MVSc B.S., Louisiana State University.

Mahrous, A.H. (2002): Epizootiological study on the role of stray dogs and rats as carriers for brucella infection. PhD. Thesis Infect. Dis. Fac.Vet.Med. Beni-Suef Cairo University.

Mobarak, S.A; Aparicio, E.D.; Armenta, T.J.; Adams, L.G. and Suarez, G.F. (2000): Absence of shedding of two B. abortus strains in goats after vaccination with live vaccines. Vaccine 18 (2000) 3018-3020.

Morgan, W.J.B.; Mackinnon, D.J.; Gill, K.P.W.; Cower S.G.M. and Norris, P.L.W. (1978): Standard laboratory techniques for the diagnosis of brucellosis. Repot Series No., I, Weybridge Cent. Vet. Lab., England.

Muranalini, N. and Ramasastry, P. (1999): Serological survey on the occurrence of brucellosis in domestic animals and man in Andhra Pradesh. Indian Vet J, 76, 483-484.

OIE Terrestrial Manual (2008): Bovine brucellosis, chapter 2.4.3 p 624 
Perry, Q.L. (2007): Brucella melitensis: the evaluation of a putative hemagglutinin gene's effect on virulence in the caprine model. A Dissertation Submitted to the Graduate Faculty of the Louisiana State University and Agricultural and Mechanical College in partial fulfillment of the requirements for the degree of Doctor of Philosophy.

Pfeiffer, D.U. (2002): Veterinary Epidemiology - An Introduction, Textbook; Royal Veterinary College, Hawkshead Lane, North Mymms, Hertfordshire AL9 7TA, United Kingdom.

Radostits, O.M; gay, C.C; Blood, D.C and Hinchcliff, K.W. (2000): "Veterinary Medicine" $9^{\text {th }}$ ed W.H. Saunders Co. Itd. London. New York, Philadelphia, Sydney, Printed in China.

Rajaii, M.; Naghili, B. and Pourhassan, A. (2006): Comparison of ELISA and STA tests in diagnosis of Brucellosis. Iranian Journal of Clinical Infectious Diseases 2006; 1(3):145-147 @2006 IDTMRC, Infectious Diseases and Tropical Medicine Research Center.

Robinson, A. (2003): Guidelines for coordinated human and animal brucellosis surveillance. FAO Animal production and health paper ISSN: 0254-6019.

Shalaby (1986): A survey on brucelloisi as a cause of reproductive disorders in farm animals in Egypt. PhD Thesis, Fac. Vet. Med., Cairo University.

Sözmen, M.; Erginsoy, S.D.; Genc, O.; Beytut, E. and Özcan, K. (2004): Immunohistochemical and Microbiological Detection of Brucella abortus in Aborted Bovine Fetuses. ACTA VET. BRNO 2004, 73: $465-472$. 